Phosphorus Research Bulletin Vol. 14 (2002), 69-76

\title{
SYNTHESIS AND CHARACTERIZATION OF LANTHANUM PHOSPHATE: EFFECT OF STARTING PRECURSORS
}

\author{
S.M.A. MOUSA \\ Inorganic Chem. Dept., National Research Center, Dokki, Cairo, Egypt.
}

Abstract Three powder samples of lanthanum phosphate were prepared via the precipitation method. $\mathrm{La}_{2} \mathrm{O}_{3}, \mathrm{LaCL}_{3},\left(\mathrm{NH}_{4}\right)_{3} \mathrm{PO}_{4}$ and $\mathrm{H}_{3} \mathrm{PO}_{4}$ were used as precursor materials. Chemical and thermal analyses, infrared spectra, X-ray diffraction and particle size techniques were used for characterization. The results of chemical analysis indicated that the three samples are in non-stoichiometric state which attributed to the solubility of the products in the aqueous medium and/or to the partial precipitate of $\mathrm{HPO}_{4}{ }^{2-}$ and $\mathrm{H}_{2} \mathrm{PO}_{4}{ }^{-}$species. The results of infrared spectra exhibited the specific bands of phosphate salts such $\mathrm{OH}, \mathrm{O}=\mathrm{P}-\mathrm{O}, \mathrm{P}-\mathrm{O}$ and O-P-O. A band at $1380 \mathrm{~cm}^{-1}$ corresponding to $\mathrm{PO}_{2}{ }^{2-}$ is observed in sample I and II which may due to make complexation species between the phosphates and the metal ions.

The X-ray diffraction indicated the formation of lanthanum phosphates of hexagonal structure of rhabdophane $\mathrm{LaPO}_{4} \cdot 0.5 \mathrm{H}_{2} \mathrm{O}$. DTA/TGA curves show that the prepared samples remain thermally stable at high temperatures.

\section{INTRODUCTION}

Owing to the great importance of metal phosphates particularly in electronics industry, non-linear optics, biocompatible materials, superionic conductors and ion exchangers, different trials for preparation of some specific phosphates were done $e^{1-4}$. Among the metal phosphates, the rare earth phosphates have a variety of potentially beneficial properties, including very low solubility in water, high thermal stability and high index of refraction. Guo et $\mathrm{al}^{5}$ succeeded in producing rare earth orthophosphate $\left(\mathrm{RE}-\mathrm{PO}_{4}\right)$ using a sol-gel technique based on the reaction between their salts and phosphoric acid in aqueous or ethanolic media. Allal et $\mathrm{al}^{6}$ found that the prepared rare earth phosphates and their substitution with $\mathrm{Ag}$ from mixtures of $\mathrm{AgNO}_{3},\left(\mathrm{NH}_{4}\right)_{2} \mathrm{HPO}_{4}$ and $\mathrm{La}_{2} \mathrm{O}_{3}$

Received August 5, 2002; Accepted October 18, 2002 
crystallized in a triclinic system. $\mathrm{LaPO}_{4}$ powder was synthesized by using the precipitation method ${ }^{7}$. Depending on synthesis conditions, the $\mathrm{La} \mathrm{PO}_{4} \cdot 0.5 \mathrm{H}_{2} \mathrm{O}$ powder has the monoclinic structure or hydrated hexagonal structure.

Some metal phosphates, $\mathrm{AlPO}_{4}, \mathrm{FePO}_{4}, \mathrm{Na}$-phosphates and $\mathrm{Zr}_{3}\left(\mathrm{PO}_{4}\right)_{2}$ were previously synthesized by the classical and the sol-gel methods in our laboratory ${ }^{8-12}$. As continueous, the present work is aimed to synthesize $\mathrm{LaPO}_{4}$ by different methods depending on various precursor materials.

\section{EXPERIMENTAL}

$\mathrm{La}_{2} \mathrm{O}_{3}, \mathrm{HNO}_{3},\left(\mathrm{NH}_{4}\right)_{3} \mathrm{PO}_{4}, \mathrm{LaCl}_{3}$ and $\mathrm{H}_{3} \mathrm{PO}_{4}(85 \%)$ of analar grade were used as the starting materials. Depending on the precursor material, $\mathrm{LaPO}_{4}$ was prepared by using three precipitation methods.

Method (I) depends on the dissolution of $\mathrm{La}_{2} \mathrm{O}_{3}$ in nitric acid solution and using triammonium phosphate as precipitating agent according to the following equations.

$$
\begin{aligned}
& \mathrm{La}_{2} \mathrm{O}_{3}+6 \mathrm{HNO}_{3} \rightarrow 2 \mathrm{La}\left(\mathrm{NO}_{3}\right)_{3}+3 \mathrm{H}_{2} \mathrm{O} . \\
& \mathrm{La}\left(\mathrm{NO}_{3}\right)_{3}+\left(\mathrm{NH}_{4}\right)_{3} \mathrm{PO}_{4} \rightarrow \underset{\downarrow}{ } \mathrm{La} \mathrm{PO}_{4}+3 \mathrm{NH}_{4} \mathrm{NO}_{3}
\end{aligned}
$$

Method (II) precipitation of $\mathrm{LaPO}_{4}$ from its chloride ( $0.1 \mathrm{M}$ solution),

$$
\mathrm{LaCl}_{3}+\left(\mathrm{NH}_{4}\right)_{3} \mathrm{PO}_{4} \rightarrow \downarrow \mathrm{La} \mathrm{PO}_{4}+3 \mathrm{NH}_{4} \mathrm{Cl}
$$

Method (III) by the reaction between ( $1 \mathrm{M}) \mathrm{H}_{3} \mathrm{PO}_{4}$ and $(0.05 \mathrm{M}) \mathrm{LaCl}_{3}$, in this case phosphoric acid was added dropwise to avoid formation of other phosphates.

$$
\mathrm{LaCL}_{3}+\mathrm{H}_{3} \mathrm{PO}_{4} \rightarrow \downarrow \mathrm{LaPO}_{4}+3 \mathrm{HCL}
$$


In all cases, the precipitates were separated, washed and dried at $\sim 80^{\circ} \mathrm{C}$. The products were characterized by chemical and thermal analyses, infrared spectra and X-ray diffraction. Also, the specific surface area were measured by BET method (micromerities ASAP 2000).

The chemical analysis was carried out by inductively coupled plasma (ICP). Infrared spectra were performed using JASCO FT/CR$3000 \mathrm{E}$ infrared spectrophotometer (Japan). X-ray diffraction analysis was carried out for the samples by means of a chart recording Philips PW, 1790, X-ray diffractmeter (Holland) using copper ( $\mathrm{Cu \alpha}$ ) radiation. The identification of the constituents has been accomplished through the use of the ASTM cards by determining the d-values of the different atomic planes and their relative intensities. DTA and TGA were performed in air with heating rate $5^{\circ} \mathrm{C} / \mathrm{m}$ by using Shimadzu DTA-50 and TGA-50 and Perkin-Elmer 7- series.

\section{RESULTS AND DISCUSSION}

The chemical analysis of the prepared samples shows that $\mathrm{La}=0.32$, 0.33 and $0.33 \times 10^{2}$ mole $^{-1}$ for samples I, II and III respectively, while $\mathrm{P}=0.39$ mole $^{-1}$. This results indicated that the three samples are in nonstoichiometric state where $\mathrm{La} / \mathrm{P}=\sim 0.9$. This may due to the solubility of some products in aqueous medium $(0.014 \mathrm{mg} / \mathrm{l})$ and/or to the partial precipitate of $\mathrm{HPO}_{4}^{2-}$ and $\mathrm{H}_{2} \mathrm{PO}_{4}^{-}$species leading to chemical composition that could be written as ${ }^{7}$,

$$
\mathrm{La}_{(1-\mathrm{x}) / 3} \quad\left(\mathrm{PO}_{4}\right)_{1-\mathrm{x}} \cdot \quad\left(\mathrm{H} \mathrm{PO}_{4}, \mathrm{H}_{2} \mathrm{PO}_{4}\right)_{\mathrm{x}} \cdot \mathrm{nH}_{2} \mathrm{O}
$$

The IR spectra of $\mathrm{LaPO}_{4}$ prepared by the three methods are shown in Fig. 1. In all cases, residual $\mathrm{OH}$ absorption around $\sim 3500 \mathrm{~cm}^{-1}$ is observed. The observed bands around $1610-1620 \mathrm{~cm}^{-1}$ are probably associated with the water bending mode. The main peaks which 


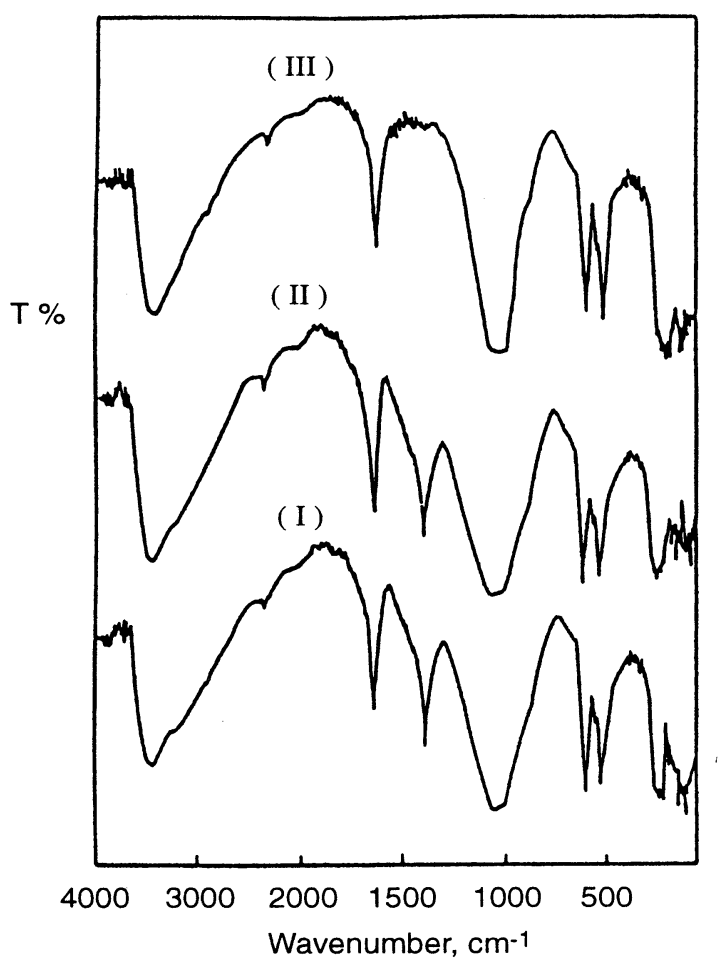

FIGURE 1 IR spectra of lanthanum phosphate.

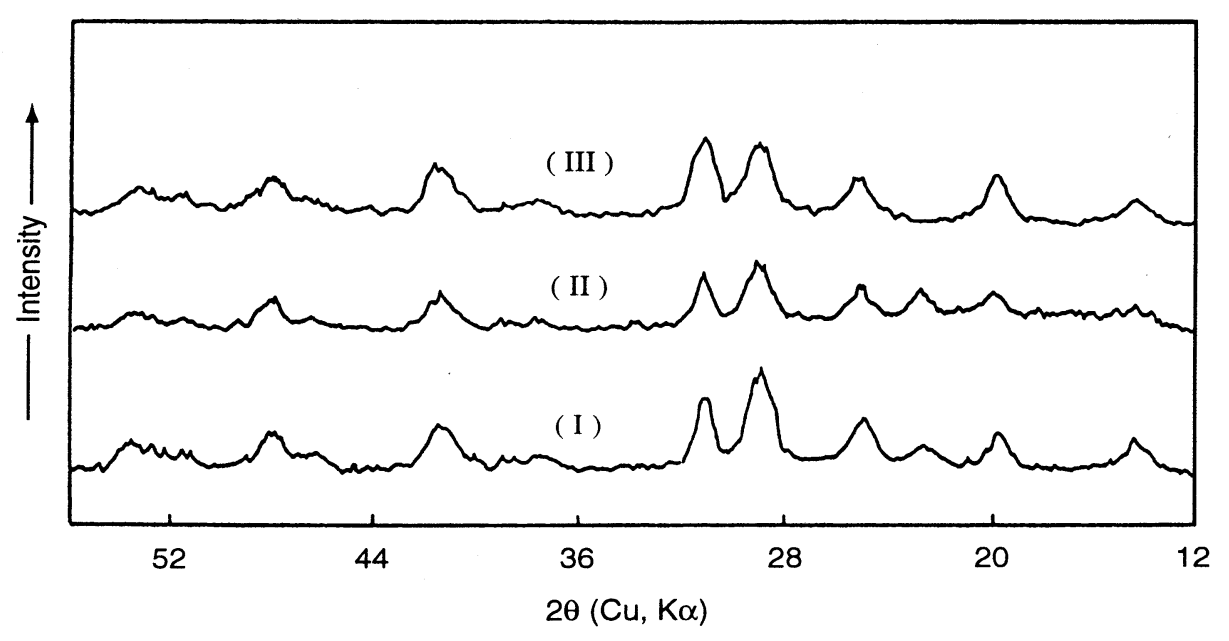

FIGURE 2 XRD patterns of lanthanum phosphate. 
characterized the phosphate groups were observed at $1040 \mathrm{~cm}^{-1}$ specified $\mathrm{P}-\mathrm{O}$ stretch, $610 / 630$ corresponding to $\mathrm{O}=\mathrm{P}-\mathrm{O}$ bend and $\mathrm{O}-\mathrm{P}-\mathrm{O}$ at 540 $\mathrm{cm}^{1}$. A band at $1380 \mathrm{~cm}^{1}$ corresponding to $\mathrm{PO}_{2}{ }^{2-}$ which observed in samples I and II only indicating the substitution of $\mathrm{PO}_{4}^{3-}$ by $\mathrm{H}_{2} \mathrm{PO}_{4}^{2-}$ ion during the precipitation process especially at low $\mathrm{pH}$ value ${ }^{13}$. This finding is in agreement with Byrne et al, where they observed that trivalent rare earth elements tend partially to make complexation species according to the following equilibrium states ${ }^{14}$.

$$
\begin{aligned}
& \mathrm{M}^{3+}+\mathrm{HOP}_{4}^{2-} \longleftrightarrow \mathrm{MHPO}_{4}^{+} \\
& \mathrm{M}^{3+}+\mathrm{H}_{2} \mathrm{PO}_{4}^{-} \longleftrightarrow \mathrm{MH}_{4} \mathrm{PO}^{2+}{ }_{4}
\end{aligned}
$$

These complexes may cause the departure of $\mathrm{La} / \mathrm{P}$ mole ratio than unity . In case of sample III, the peak $\left(1380 \mathrm{~cm}^{-1}\right)$ was not observed which my due to step-wise addition of $\mathrm{H}_{3} \mathrm{PO}_{4}$.

XRD patterns of the three prepared phosphate Fig.2 show that all the processes lead to single phase lanthanium phosphates of hexagonal structure of rhabdophane $\mathrm{LaPO}_{4} \cdot 0.5 \mathrm{H}_{2} \mathrm{O}$ according to ASTM card (40635). In addition a peak corresponding to ammonium phosphate is appeared in case of samples I and II.

Fig. 3 represents the thermogravimetric analysis of the prepared samples. The results showed two endothermic peaks at $\sim 130$ and $\sim$ $246^{\circ} \mathrm{C}$. The first peak is attributed to the loss of physisorbed water and the second one is related to the loss of the hydration water of the rhabdophane phosphates $\mathrm{La} \mathrm{PO}_{4} .0 .5 \mathrm{H}_{2} \mathrm{O}$ as detected from the X-ray patterns. DTA/TGA curves beyoned $\sim 300^{\circ} \mathrm{C}$ up to $\sim 1000^{\circ} \mathrm{C}$ did not appear any additional observation. This indicate, that $\mathrm{La} \mathrm{PO}_{4}$ prepared by the three methods remain thermally stable at the high tempratures ${ }^{15}$.

Specific surface area of the powders issued from the three methods 

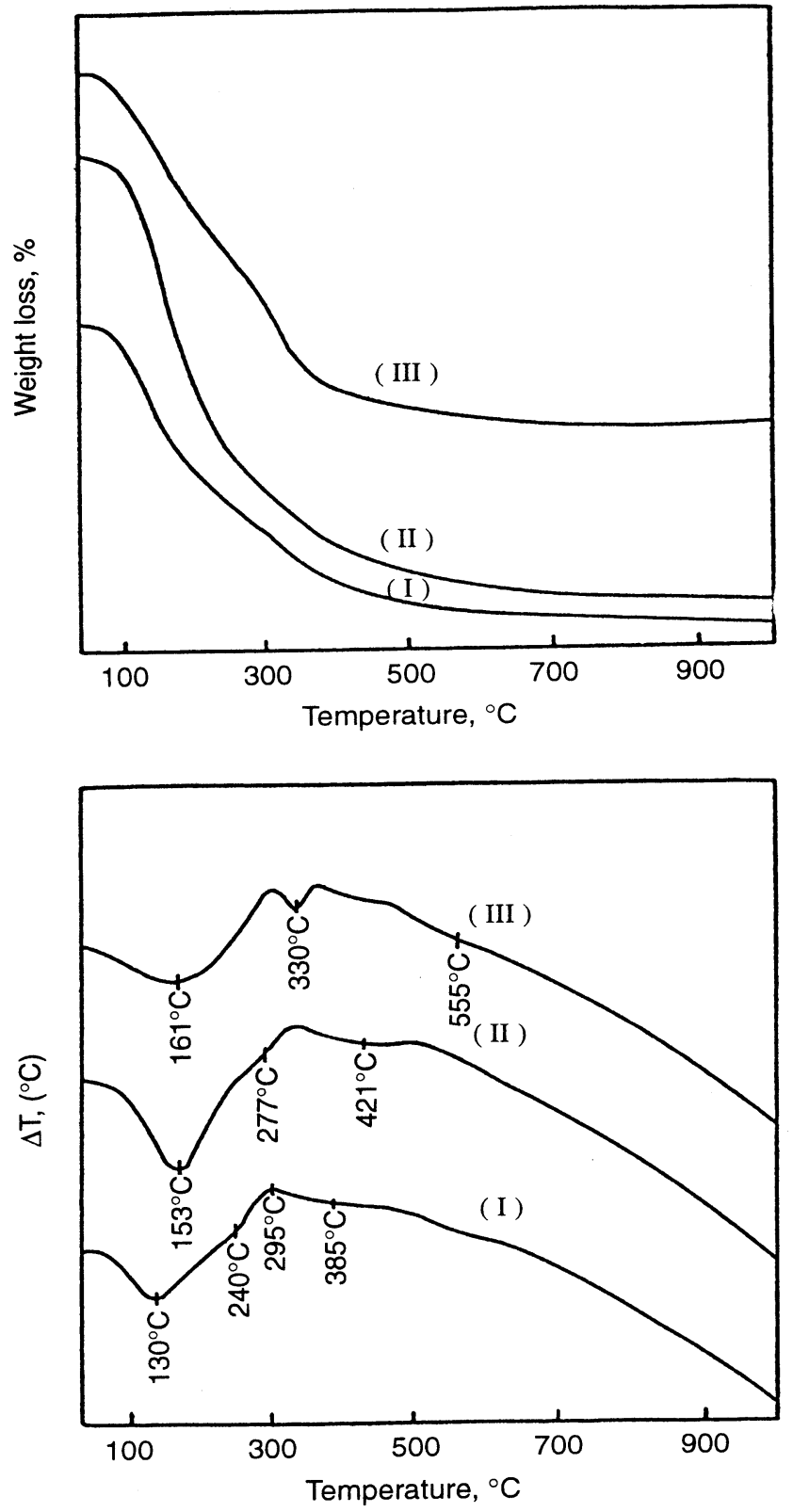

FIGURE 3 TG and DTA of lanthanum phosphate. 
I, II and III are nearly similar where it equals to $35.65,40.22$ and 37.51 $\mathrm{m}^{2} / \mathrm{g}$ respectively.

\section{REFERENCES}

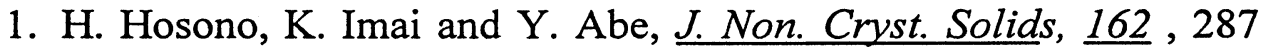
(1993).

2. H. Miyazaki, H. Kojima, A. Hiraiwa, Y. Himma and K. Murakami, J. Electro. Chem. Soc., 141, 734 (1994).

3. C.Y. Huang, D.K. Agrawal, H.A. Mckinstry and S.Y. Limaye, J. Mater. Res., 9, 2005 (1994).

4. C. Dayamond, R.V. sarma, G. Bhikshamaiah and M. Salagram, J. Non-cryst solids., 167, 122 (1994).

5. Y. Guo, P. Woznicki, A. Barkatt, E.E. Saad and I.G. Talmy, J. Mater. Res., 11, 639 (1996).

6. M.A. Allal, M. Daoud, B. Tanouti, A. Ammar and D. Zambon, Ann. Chim. Sci. Mat, 23, 125 (1998).

7. C. Penot, E. Champion and P. Goursat, Phos. Res. Bull., 10, 307 (1999).

8. A.A. Hanna, N.S. Youssef and A.F. Ali, Egypt. J. Chem., 141199 (1998).

9. A.A. Hanna, N.S. Youssef and A.F. Ali, Egypt J. Chem., $\underline{42}, 421$ (1999).

10.A.A. Hanna, M.Sh. Khalil and A.F. Ali, Phos.Res. Bull., 11, 94 (2000).

11.M. Sh. Kalil, A.A. Hanna and M.A. El-Sayed, Phos. Res. Bull., 12, 77 (2001). 
12.W.F. Linke and W.F. Seidell "Solubilities of Inorg. And Metal Organic Compounds (Van Nostrand, Princeton, NJ.) (1958).

13.R.H. Byrne and K.Kim., Geochemica et Casmochimica Acta, 57, 519 (1993).

14.R.H. Byrne, J.H. Lee and L.S. Bingler, Geochimica et Casmochimica Acta, 55, 2729 (1991).

15.A. Mortier, J. Lemaitre and P.G. Rouxhet, Thermochimica Acta, 143, 265 (1989). 